\title{
Aging behavior of the HfNbTaTiZr high entropy alloy
}

\author{
N.D. Stepanov ${ }^{a, *}$, N.Yu. Yurchenko ${ }^{a}$, S.V. Zherebtsov ${ }^{a}$, M.A. Tikhonovsky ${ }^{b}$, G.A. Salishchev ${ }^{a}$ \\ ${ }^{a}$ Laboratory of Bulk Nanostructured Materials, Belgorod State University, Belgorod 308015, Russia \\ ${ }^{\mathrm{b}}$ National Science Center "Kharkov Institute of Physics and Technology" NAS of Ukraine, Kharkov 61108, Ukraine
}

\section{A R T I C L E I N F O}

Article history:

Received 25 July 2017

Received in revised form 6 September 2017

Accepted 25 September 2017

Available online 27 September 2017

\section{Keywords:}

Metals and alloys

High entropy alloys

Phase transformation

Heat treatment

TEM

\begin{abstract}
A B S T R A C T
The HfNbTaTiZr high entropy alloy was produced by vacuum arc melting, homogenized at $1200^{\circ} \mathrm{C}$, and annealed at $600-1000{ }^{\circ} \mathrm{C}$ for $1-100 \mathrm{~h}$. Structure and microhardness of the annealed alloy were investigated. A strong increase of microhardness after aging treatment at $600{ }^{\circ} \mathrm{C}$ was found. Formation of second hcp phase particles in the bcc matrix after annealing at 600 and $800^{\circ} \mathrm{C}$ was also revealed. Effect of precipitation of second phase particles on microhardness was analyzed.
\end{abstract}

(ㄷ) 2017 Elsevier B.V. All rights reserved.

\section{Introduction}

High entropy alloys (HEAs) are generally defined as multicomponent ( $\geq 5$ elements) nearly equiatomic (the concentration of the principle components is 5-35 at.\%) metallic alloys [1-3]. The initial idea behind this concept was that high entropy of mixing natural for the multicomponent equiatomic alloys can make the formation of solid solution phases more preferable over intermetallic ones [1]. Several HEAs with single solid solution phase structures have been found so far. The best-known example is the equiatomic CoCrFeNiMn alloy with a single face-centered cubic (fcc) structure introduced by Cantor [4-7]. Several body-centered cubic (bcc) structured HEAs were also introduced [8,9]. These bcc HEAs are mostly based on refractory elements, and the beststudied example among them is the HfNbTaTiZr alloy [10-13].

Although the initial HEA concept emphasized formation of a single solid solution phase, the strength of many commercial structural metallic materials increases usually by second phases in order to meet the required characteristics [14]. However approaches to precipitates formation in a disordered matrix in refractory elements based HEAs in a controlled way are still unclear. For instance, it is already established by O.N. Senkov et al. that the HfNbTaTiZr alloy (i) has the single bcc phase after homogenization treatment [10]; (ii) second phase particles can

\footnotetext{
* Corresponding author.

E-mail addresses: stepanov@bsu.edu.ru, stepanov.nikita@icloud.com (N.D. Stepanov)
}

be found in the alloy after deformation at elevated temperatures or annealing $[11,13]$. But the possibility of hardening heat treatment of the alloy has not been revealed yet. Therefore, in this work we have studied an annealing effect on the hardness and structure of the homogenized equiatomic HfNbTaTiZr alloy.

\section{Materials and methods}

The equiatomic HfNbTaTiZr alloy was produced by vacuum arc melting. Pure elements (each of them at least 99.9\% purity) were used as the raw material. The ingot with dimensions $\approx 8 \times 12 \times 40 \mathrm{~mm}^{3}$ was remelted 5 times to ensure the chemical homogeneity. The obtained alloy had an equiatomic composition (20 \pm 1 at.\% of each component). The as-cast alloy was homogenized in vacuum at $1200{ }^{\circ} \mathrm{C}$ for $24 \mathrm{~h}$. After homogenization, the alloy was annealed in vacuum at 600,800 and $1000^{\circ} \mathrm{C}$ for 1 $100 \mathrm{~h}$. The microhardness of the alloy was measured with $200 \mathrm{~g}$ load. Each data point was the average of at least 20 individual measurements. The structure was characterized by X-ray diffraction (XRD), scanning (SEM) and transmission (TEM) electron microscopy. The XRD measurements were performed using a Riguku diffractometer with $\mathrm{Cu}$ radiation. A Quanta 200 3D microscope with energy dispersive (EDX) detector was used for the SEM analysis. TEM images were obtained using a JEOL JEM-2100 microscope equipped with EDX detector. Samples for the TEM investigation were prepared by twin-jet electropolishing in a mixture of $5 \mathrm{~mL}$ $\mathrm{HF}+45 \mathrm{~mL} \mathrm{H} 2 \mathrm{SO} 4$ in 950 methanol at $-35^{\circ} \mathrm{C}$. 


\section{Results and discussion}

In the initial homogenized condition the HfNbTaTiZr alloy had a single phase bcc structure (Fig. 1a). The lattice parameter of the bcc phase was $0.340 \mathrm{~nm}$. SEM-BSE image (Fig. 1b) shows the presence of coarse grains with the mean size of $185 \pm 75 \mu \mathrm{m}$.

Fig. 2 shows the microhardness of the HfNbTaTiZr alloy depending on the annealing conditions (temperature and time). The hardness of the alloy in the homogenized condition was $370 \mathrm{HV}$. Annealing for $1 \mathrm{~h}$ at $800{ }^{\circ} \mathrm{C}$ and $1000^{\circ} \mathrm{C}$ resulted in slight $(\approx 10 \%)$ increase of the microhardness. Further annealing for 10 and $100 \mathrm{~h}$ at these temperatures caused a decrease of hardness approximately to the initial level. The hardness was somewhat higher after annealing at $800{ }^{\circ} \mathrm{C}$ for all soak time. Annealing at $600{ }^{\circ} \mathrm{C}$ had much more pronounced effect: after 1-h annealing the microhardness rose to $470 \mathrm{HV}$. An increase in annealing time to $10 \mathrm{~h}$ resulted in further increase of the microhardness to $500 \mathrm{HV}$, i.e. an increment in hardness by $\approx 35 \%$ in comparison with the initial condition was achieved. Further increase of annealing time resulted in gradual softening. Nevertheless, the microhardness of the alloy annealed at $600{ }^{\circ} \mathrm{C}$ for $15-100 \mathrm{~h}$ was still significantly higher than that in the initial condition (450-465 HV vs. $370 \mathrm{HV}$, Fig. 2).

To understand the reasons of hardening of the HfNbTaTiZr alloy after annealing, microstructural studies were performed. The SEM investigation of the HfNbTaTiZr alloy after 10-h annealing at $600{ }^{\circ} \mathrm{C}$ had revealed some second phase particles in grain boundaries; however more detailed TEM study (Fig. 3a) had shown numerous

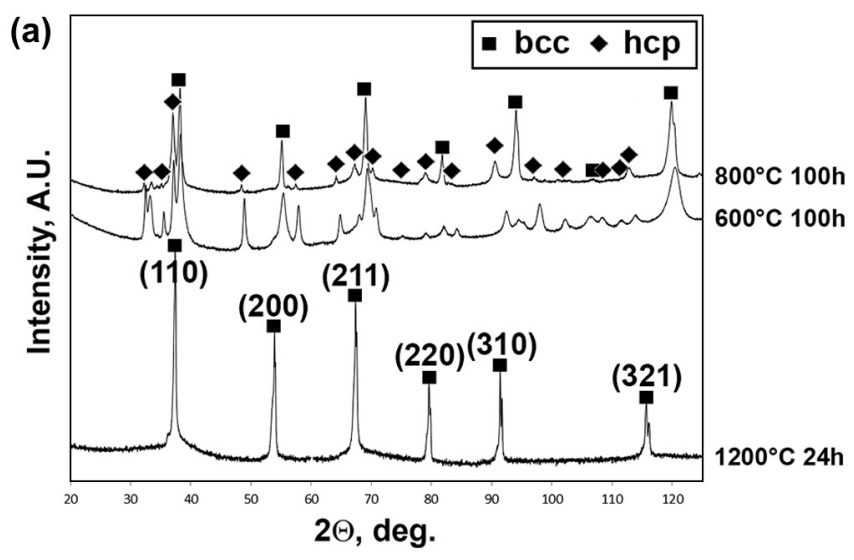

(b)

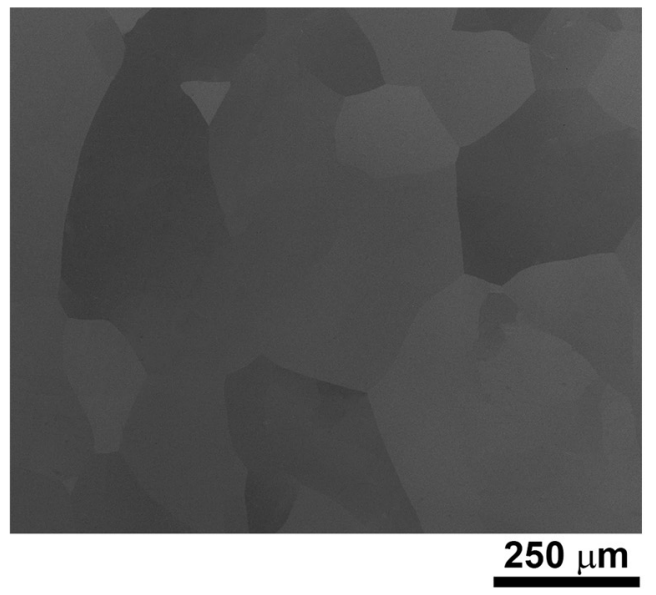

Fig. 1. Structure of the HfNbTaTiZr alloy: XRD patterns of the alloy in the homogenized and annealed $\left(600^{\circ} \mathrm{C}, 100 \mathrm{~h}\right.$, and $\left.800^{\circ} \mathrm{C}, 100 \mathrm{~h}\right)$ conditions (a) and SEM-BSE image of the alloy in the homogenized condition (b).

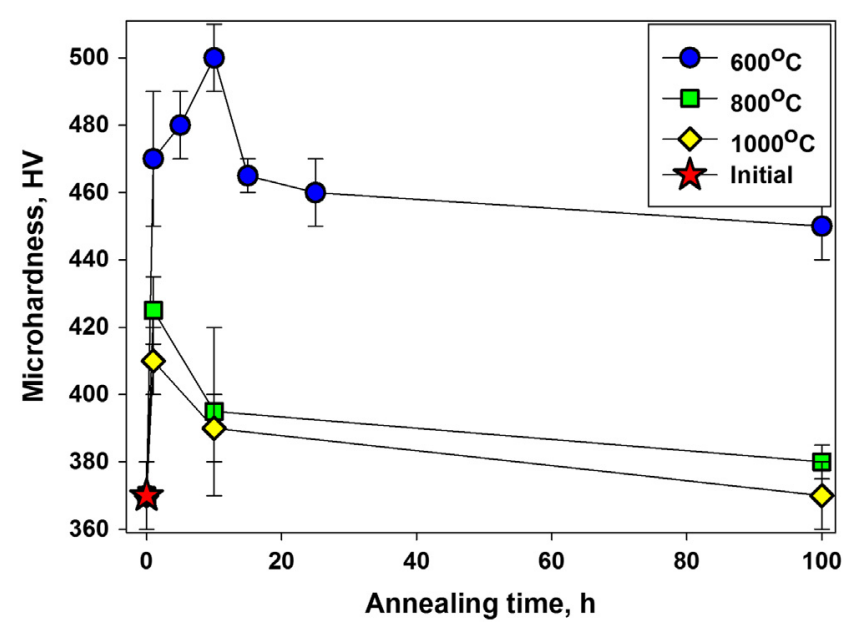

Fig. 2. The dependence of microhardness of the HfNbTaTizr alloy on annealing temperature and time.

nano-sized particles with a hexagonal close-packed (hcp) lattice $(\mathrm{a}=0.297 \mathrm{~nm} ; \mathrm{c}=0.478 \mathrm{~nm})$. Their volume fraction was $\sim 20 \%$ and the average diameter was $25 \mathrm{~nm}$. The particles were enriched with $\mathrm{Hf}$ and $\mathrm{Ta}$ ( $\approx 25$ at.\% each). The grain boundary particles were much coarser (several hundred $\mathrm{nm}$ ), but had the same crystal structure and chemical composition. Further increase of the soak time at $600{ }^{\circ} \mathrm{C}$ to $100 \mathrm{~h}$ resulted in the complete decomposition of the initial single phase structure and the formation of a fine basket-weave-like structure (Fig. $3 \mathrm{~b}$ ). According to the XRD results (Fig. 1a), the structure was composed of the bcc and hcp phases. Note that the lattice parameter of the bcc phase decreased in comparison with the initial condition, possibly due to changes in the chemical composition. At a higher temperature $\left(800^{\circ} \mathrm{C}\right)$, the second phase particles with the average size of several microns appeared after 10 and $100 \mathrm{~h}$ annealing (Fig. $3 \mathrm{c}$ and d respectively). The particles were mainly found in (sub)grain boundaries in a form of characteristic chains inside bcc grains. Some individual particles were also observed however. The volume fraction of the particles increased from $12 \%$ to $21 \%$ with an increase of annealing time from 10 to $100 \mathrm{~h}$. The particles were enriched with $\mathrm{Hf}$ and Ta and in accordance with the XRD results (Fig. 1a) had the hcp structure. Note that the previous studies have reported the formation of the second phase with bcc structure in the HfNbTaTiZr alloy after annealing at $800{ }^{\circ} \mathrm{C}[11,15]$. However, the experimental conditions like initial state (homogenized vs cold-rolled) and annealing time (10-100 h vs $2 \mathrm{~h}$ ) in present and previous works were different. This is probably the reason for the discrepancy between the obtained results. The investigations of the HfNbTaTiZr alloy after annealing at $1000^{\circ} \mathrm{C}$ (not shown) had revealed predominantly a single-phase structure similar to that observed in the homogenized condition, however with a tiny fraction of unidentified second phase particles in grain boundaries.

The presence of nano-sized second (hcp) phase particles in the HfNbTaTiZr alloy after annealing (aging) at $600{ }^{\circ} \mathrm{C}$ for $10 \mathrm{~h}$ (Fig.3a) most likely resulted in the pronounced increase in hardness (Fig. 2). The hardening effect of the precipitates can be estimated using the Ashby-Orowan equation [16]:

$\Delta \sigma=0.538 G b\left(\frac{\sqrt{f}}{d}\right) \ln \left(\frac{d}{2 b}\right)$

where $G$ is the shear modulus, $b$ is the Burgers vector, $f$ is the volume fraction of particles, and $d$ is their diameter. The $f$ and $d$ values were given above. The shear modulus of $\approx 100 \mathrm{GPa}$ for the HfNbTaTiZr alloy at room temperature was reported in [11], the Burgers 


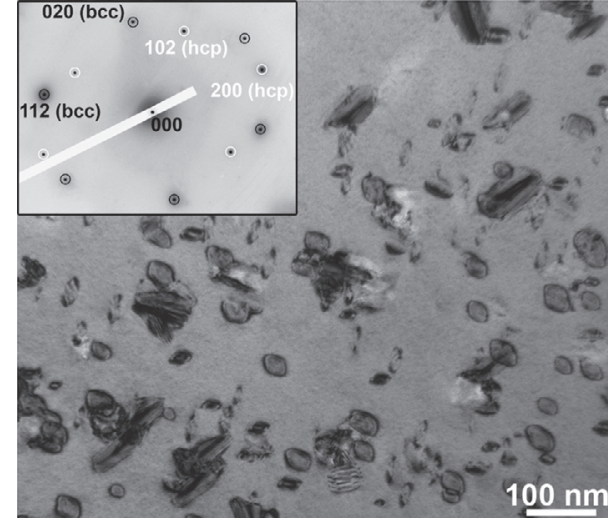

(a)

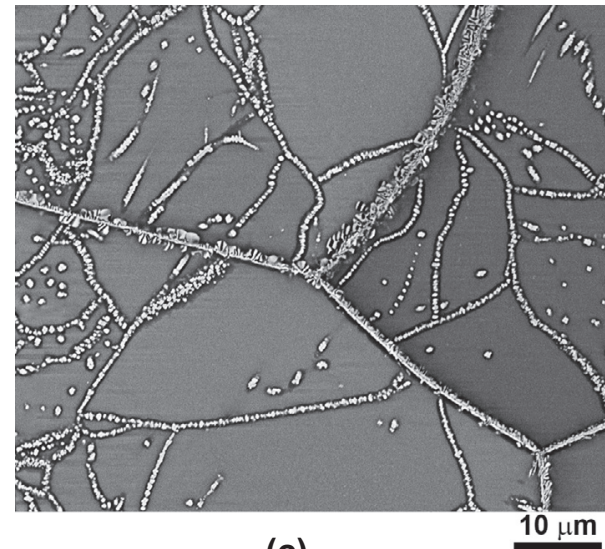

(c)

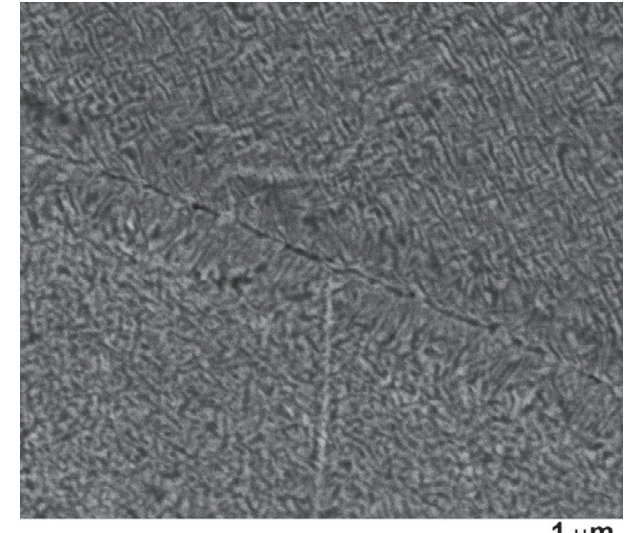

(b)

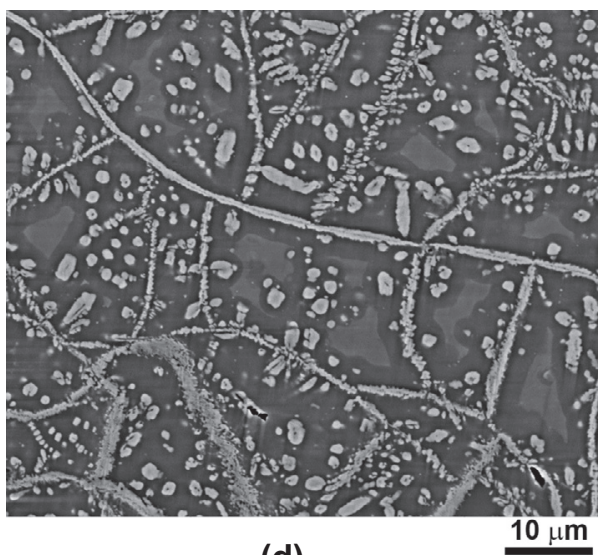

(d)

Fig. 3. Microstructure of the HfNbTaTiZr alloy after annealing at $600{ }^{\circ} \mathrm{C}$ (a, b), $800{ }^{\circ} \mathrm{C}$ (c, d) for 10 (a, c) and 100 (b, d) hours.

vector can be estimated as of $0.245 \mathrm{~nm}$ using the experimental bcc lattice parameter. Converting the results of Eq. (1) to microhardness $\mathrm{HV}$, we had obtained the microhardness increase $\Delta H V \approx 110$. This value is consistent with the experimental increase in the microhardness by $130 \mathrm{HV}$ (Fig. 3) and proves that the precipitation of the nanoscale hcp particles after $10 \mathrm{~h}$ annealing at $600{ }^{\circ} \mathrm{C}$ can cause a significant increase of hardness. It seems reasonable to suggest that the coarsening of the second phase particles due to longer annealing (Fig. 3b) resulted in a diminishing of strengthening effect in accordance with Eq. (1). Similarly, the micron-sized hcp particles produced by annealing at $800{ }^{\circ} \mathrm{C}$ (Fig. $3 \mathrm{C}$ and d) did not cause significant strengthening (Fig. 2).

In general, the obtained data demonstrate that a significant strengthening of the HfNbTaTiZr alloy can be achieved by an aging treatment due to the precipitation of the nano-sized second phase particles. This is an important result since both the work hardening [11] and grain refinement [17] have a weak effect on strength of the alloy. For instance, microhardness of the alloy after cold rolling with $86.4 \%$ thickness reduction is $366 \mathrm{HV}$ [11] (compare with 500 $\mathrm{HV}$ after annealing at $600^{\circ} \mathrm{C}$ ). It should be also noted that in the CoCrFeNiMn alloy precipitation of second phases did not result in a pronounced hardening $[18,19]$. On the other hand, the microstructural observations demonstrated that the hightemperature single phase structure of the alloy (Fig. 1) became drastically unstable at lower temperatures (i.e. Fig. 3b). This might limit the potential application of the HfNbTaTizr alloy as a hightemperature material. Possibly, the chemical composition of the alloy could be modified to improve both the structural stability and hardening response; however this is the task for further investigations.

\section{Conclusions}

The effect of annealing at $600-1000{ }^{\circ} \mathrm{C}$ for $1-100 \mathrm{~h}$ on the structure and microhardness of the homogenized $\left(1200^{\circ} \mathrm{C}, 24 \mathrm{~h}\right)$ HfNbTaTiZr alloy was investigated. It was revealed that the microhardness increased from $370 \mathrm{HV}$ in the homogenized condition to $500 \mathrm{HV}$ after aging at $600{ }^{\circ} \mathrm{C}$ for $10 \mathrm{~h}$. The hardening was associated with the precipitation of the Hf, Ta-rich hcp particles in the bcc matrix of the alloy. The formation of the second hcp phase was also observed after annealing at $800^{\circ} \mathrm{C}$; however the hardening effect was noticeably lower due to the larger size of the particles. At both temperatures, the fraction of hcp phase increased with the increase of soak time.

\section{Acknowledgments}

The authors gratefully acknowledge the financial support from Russian Science Foundation, Grant № 14-19-01104. The authors are also grateful to Joint Research Center "Materials and Technologies", Belgorod State University, for the assistance with instrumental analysis.

\section{References}

[1] J.-W. Yeh, S.-K. Chen, S.-J. Lin, J.-Y. Gan, T.-S, Chin, T.-T. Shun, C.-H. Tsau, S.-Y. Chang, Nanostructured high-entropy alloys with multiple principal elements: novel alloy design concepts and outcomes, Adv. Eng. Mater. 6 (2004) 299-303, https://doi.org/10.1002/adem.200300567.

[2] Y. Zhang, T.T. Zuo, Z. Tang, M.C. Gao, K.A. Dahmen, P.K. Liaw, Z.P. Lu, Microstructures and properties of high-entropy alloys, Prog. Mater. Sci. 61 (2014), https://doi.org/10.1016/j.pmatsci.2013.10.001. 
[3] D.B. Miracle, O.N. Senkov, A critical review of high entropy alloys and related concepts, Acta Mater. 122 (2017) 448-511, https://doi.org/10.1016/j. actamat.2016.08.081.

[4] B. Cantor, I.T.H. Chang, P. Knight, A.J.B. Vincent, Microstructural development in equiatomic multicomponent alloys, Mater. Sci. Eng. A 375 (2004) 213-218, https://doi.org/10.1016/j.msea.2003.10.257.

[5] F. Otto, Y. Yang, H. Bei, E.P.P. George, Relative effects of enthalpy and entropy on the phase stability of equiatomic high-entropy alloys, Acta Mater. 61 (2013) 2628-2638, https://doi.org/10.1016/j.actamat.2013.01.042.

[6] G.A. Salishchev, M.A. Tikhonovsky, D.G. Shaysultanov, N.D. Stepanov, A.V. Kuznetsov, I.V. Kolodiy, A.S. Tortika, O.N. Senkov, Effect of Mn and V on structure and mechanical properties of high-entropy alloys based on CoCrFeNi system, J. Alloys Compd. 591 (2014) 11-21, https://doi.org/10.1016/ j.jallcom.2013.12.210.

[7] M. Laurent-Brocq, A. Akhatova, L. Perrière, S. Chebini, X. Sauvage, E. Leroy, Y. Champion, Insights into the phase diagram of the CrMnFeCoNi high entropy alloy, Acta Mater. 88 (2015), https://doi.org/10.1016/j.actamat.2015.01.068.

[8] O.N. Senkov, G.B. Wilks, D.B. Miracle, C.P. Chuang, P.K. Liaw, Refractory highentropy alloys, Intermetallics 18 (2010) 1758-1765, https://doi.org/10.1016/j. intermet.2010.05.014.

[9] O.N. Senkov, G.B. Wilks, J.M. Scott, D.B. Miracle, Mechanical properties of Nb25Mo25Ta25W25 and V20Nb20Mo20Ta20W20 refractory high entropy alloys, Intermetallics 19 (2011) 698-706, https://doi.org/10.1016/j. intermet.2011.01.004.

[10] O.N. Senkov, J.M. Scott, S.V. Senkova, D.B. Miracle, C.F. Woodward, Microstructure and room temperature properties of a high-entropy TaNbHfZrTi alloy, J. Alloys Compd. 509 (2011) 6043-6048, https://doi.org/ 10.1016/j.jallcom.2011.02.171.

[11] O.N. Senkov, S.L. Semiatin, Microstructure and properties of a refractory highentropy alloy after cold working, J. Alloys Compd. 649 (2015) 1110-1123, https://doi.org/10.1016/j.jallcom.2015.07.209.
[12] J.-P. Couzinié, L. Lilensten, Y. Champion, G. Dirras, L. Perrière, I. Guillot, On the room temperature deformation mechanisms of a TiZrHfNbTa refractory highentropy alloy, Mater. Sci. Eng. A 645 (2015) 255-263, https://doi.org/10.1016/ j.msea.2015.08.024.

13] O.N. Senkov, J.M. Scott, S.V. Senkova, F. Meisenkothen, D.B. Miracle, C.F. Woodward, Microstructure and elevated temperature properties of a refractory TaNbHfZrTi alloy, J. Mater. Sci. 47 (2012) 4062-4074, https://doi org/10.1007/s10853-012-6260-2.

[14] D.B. Miracle, Critical Assessment 14: High entropy alloys and their development as structural materials, Mater. Sci. Technol. 31 (2015) 11421147, https://doi.org/10.1179/1743284714Y.0000000749.

[15] W. Wu, S. Ni, Y. Liu, M. Song, Effects of cold rolling and subsequent annealing on the microstructure of a HfNbTaTiZr high-entropy alloy, J. Mater. Res. 31 (2016) 3815-3823, https://doi.org/10.1557/jmr.2016.445.

[16] T. Gladman, Precipitation hardening in metals, Mater. Sci. Technol. 15 (1999) 30-36, https://doi.org/10.1179/026708399773002782.

[17] C.-C.C. Juan, M.-H.H. Tsai, C.-W.W. Tsai, W.-L.L. Hsu, C.-M.M. Lin, S.-K.K. Chen, S.-J.J. Lin, J.-W.W. Yeh, Simultaneously increasing the strength and ductility of a refractory high-entropy alloy via grain refining, Mater. Lett. 184 (2016) 200203, https://doi.org/10.1016/j.matlet.2016.08.060.

[18] B. Schuh, F. Mendez-Martin, B. Völker, E.P.P. George, H. Clemens, R. Pippan, A Hohenwarter, B. Volker, E.P.P. George, H. Clemens, R. Pippan, A. Hohenwarter, Mechanical properties, microstructure and thermal stability of a nanocrystalline CoCrFeMnNi high-entropy alloy after severe plastic deformation, Acta Mater. 96 (2015) 258-268, https://doi.org/10.1016/j actamat.2015.06.025.

[19] N.D.D. Stepanov, D.G.G. Shaysultanov, M.S.S. Ozerov, S.V.V. Zherebtsov, G.A.A. Salishchev, Second phase formation in the CoCrFeNiMn high entropy alloy after recrystallization annealing, Mater. Lett. 185 (2016) 1-4, https://doi.org 10.1016/j.matlet.2016.08.088. 